\title{
Comunidad Andina: ¿una organización compleja, cohesionada y coherente?
}

\author{
Eric Tremolada Álvarez* (1)
}

\section{Resumen}

Al sumar más de 50 años de existencia de integración andina, conviene preguntarse iqué tan compleja, cohesionada y coherente es su organización? si ha alcanzado un desarrollo y una madurez suficiente ¿qué garantiza la eficacia de sus normas?, y si el derecho que producen sus órganos ison fuente inmediata de derechos y obligaciones para todos aquellos a quienes afecta? Para responder estos interrogantes, transitaremos por las teorías científicas de la integración económica, por la estructura del ordenamiento andino y sus reglas de aplicación, y finalizaremos con sus instituciones políticas.

Palabras clave: Integración económica, institucionalización de la integración, supranacionalidad, derecho andino y reglas de aplicación.

\section{Andean Community: a complex, cohesive and coherent organization?}

Abstract

After more than 50 years of Andean integration, it is worth asking how complex, cohesive and coherent is its organization. If it has achieved sufficient growth and maturity, what guarantees the effectiveness of its rules? Also, if the set of laws made by its bodies is an immediate source of rights and obligations for all those affected by them. To answer these questions, we will go through the scientific theories of economic integration, the structure of the Andean code system and its rules of application, and we will finish with the analysis of its political institutions.

Keywords: economic integration, institutionalization of integration, supranational integration, Andean law and rules of application.

* Profesor e investigador en la Facultad de Finanzas, Gobierno y Relaciones Internacionales y del departamento de Derecho de los Negocios, designado por la Comisión Europea como el titular en Colombia de la Cátedra Jean Monnet de Derecho Comunitario en la Universidad Externado de Colombia. <eric. tremolada@uexternado.edu.co>.

Recibido: 14 de julio de 2020 | Revisado: 25 de julio de 2020 | Aceptado: 14 de septiembre de 2020. Para citar este artículo: Tremolada Álvarez, Eric. "Comunidad Andina: iuna organización compleja, cohesionada y coherente?". Comentario Internacional 20 (2020): 101-120. doi: 10.32719/26312549. 2020.20.1.8 


\section{Prefacio}

a institucionalidad jurídica de carácter económico, que regula la cooperación entre Estados con miras a ampliar intercambios comerciales, es lo que se denomina integración económica. Se trata de un marco de relaciones interestatales que gestiona intereses comunes mediante reglas y órganos, que permiten inferir el grado de compromiso que los estados asumen en procura de sus logros.

La gestión de estos intereses comunes implica un desprendimiento de competencias nacionales sobre la base de obligaciones recíprocas, creando ordenamientos jurídicos autónomos que, según el nivel o estamento de integración pactado, contará con estructuras independientes capaces de generar e imponer obligaciones válidas y eficaces que no deberían de necesitar consentimiento posterior del Estado miembro.

Completados cincuenta años de integración andina, conviene reflexionar que tan compleja, cohesionada y coherente es su organización, si ha alcanzado un desarrollo y una madurez suficiente para garantizar la eficacia de sus normas, y si estas son fuente inmediata de derechos y obligaciones para todos aquellos a quienes afecta. ${ }^{1}$ Para esto -dentro de las limitaciones editoriales- transitaremos por el contexto teórico de la integración económica, y por las luces y sombras de la estructura del ordenamiento andino y sus reglas de aplicación.

\section{Fundamentos}

\section{de la integración económica}

Los fundamentos que soportan el marco teórico de la integración económica se construyeron sobre dos estudios, uno de la década de 1950: la Teoría de las uniones aduaneras de Jacob Viner, ${ }^{2}$ economista canadiense de origen rumano, fundador de la Escuela de Chicago, y otro de la década de

1. Liñán Nogueras apoyado en Bobbio, precisa que "una determinada norma es eficaz por una compleja organización que determina la naturaleza y entidad de las sanciones, las personas que deben aplicarlas y su ejecución". Ver Martín Mangas y Diego Liñan, Instituciones y Derecho de la Unión Europea (Madrid: Tecnos, 2005), 332.

2. Jacob Viner, The Customs Union Issue (Nueva York: Fundación Carnegie para la Paz Internacional, 1950). 
1980: la Teoría de la integración económica, de Béla Alexander Balassa, economista húngaro, profesor renombrado de la Universidad Johns Hopkins y consultor del Banco Mundial. ${ }^{3}$ Este soporte contextual y otros análisis, nos permiten afirmar que la integración es una institución jurídica de carácter económico, donde los Estados miembros cooperan para ampliar sus intercambios comerciales, se basa en acuerdos que configuran espacios económicos (zonas) donde los países se conceden determinadas ventajas, según su voluntad política. Así, la configuración de la zona responderá a la etapa o estamento de integración económica pactada. ${ }^{4}$

De ahí, que, si las Partes de un tratado establecen una zona en la que, de manera recíproca, eliminarán o disminuirán significativamente sus aranceles y las barreras no arancelarias a su comercio, se configura una zona de libre comercio. Si sobre la base de lo anterior se pacta, además, el establecimiento de un arancel externo común para el comercio con terceros países o regiones, se configura una unión tarifaria también denominada unión de consumidores.

Cuando a una unión tarifaria se le crea un organismo supranacional de aduanas que recibe y distribuye los ingresos fiscales percibidos por los productos de terceros países que entran a la zona, estaremos frente a una unión aduanera. Unión tarifaria y unión aduanera no son conceptos análogos, tienen diferencias sustanciales, esto es que el arancel que pagan los bienes y/o servicios de los países ajenos a la zona se queda, en el caso de la unión tarifaria, en el fisco del país por el que ingresa, mientras que en la unión aduanera, independientemente del lugar por el que ingresa, va a parar a la hacienda común. ${ }^{5}$ Además, la unión tarifaria necesita un altísimo grado de cooperación y articulación de las aduanas nacionales para evitar costos adicionales,

3. Bela Balassa, "Tariff Reductions and Trade in Manufactures among the Industrial Countries", en Comparative Advantage, Trade Policy and Economic Development (London: Harvester Wheatsheaf, 1989), 131-9; "Trade Creation and Trade Diversion in the European Common Market: An Appraisal of the Evidence", Manchester School of Economic and Social Studies 42, n. ${ }^{\circ} 2$ (1974): 93-135.

4. Erick Tremolada, "La Alianza del Pacífico: ¿marketing sin contenido?", en Nuevas propuestas de integración regional: tendencias y retos de transformación, ed. Catherine Ortiz y Edgar Vieira (Bogotá: Fondo Editorial-Ediciones Universidad Cooperativa, 2019), 267-305; "La Alianza del Pacífico: iuna sobrevalorada integración?", Studi sull' integrazione europea 11, n. ${ }^{\circ} 1$ (2016): 21-40; “¿La Alianza del Pacífico facilita la inserción de Colombia en la región Asia Pacífico?", Papel Político 19, n. 2 (2014): 721-52.

5. Roberto Dromi, Miguel Angel Ekmekdijan y César Rivera, ed., Derecho comunitario, sistemas de integración régimen del Mercosur (Buenos Aires: Ciudad Argentina, 1995). 
mientras que en la unión aduanera la aduana supranacional es la que toma las decisiones y las aduanas nacionales son meros ejecutores de esta.

Si a una unión aduanera consolidada, además, de la eliminación de aranceles y barreras arancelarias, la definición de un arancel externo común y la creación de un ente supranacional de aduana, se le suma la liberación de capital y trabajo, estaremos frente al Mercado Común. A partir de este estamento, evidenciaremos prácticamente la fusión de los espacios económicos nacionales, tal como lo observó el Tribunal de Justicia de las Comunidades Europeas en su sentencia del 5 de mayo de 1982, al resolver el asunto Schul, definiendo al mercado común como la fusión de los mercados nacionales en un mercado único que funcione en condiciones lo más similares posibles a las de un verdadero mercado interior, ${ }^{6}$ donde se da libertad plena a bienes, servicios, capital y trabajo, por lo que es imprescindible un altísimo grado de cooperación para armonizar políticas macroeconómicas y sectoriales.

Una de las grandes dificultades por las que atravesó la Unión Europea para superar la crisis financiera de 2008, fue que en materia monetaria las competencias transferidas al Banco Central Europeo no eran plenas y de ahí que hubiera que concertar decisiones con los respectivos gobiernos nacionales. El Tratado de Estabilidad, Coordinación y Gobernanza en la Unión Económica y Monetaria, acuerdo firmado el 2 marzo de 2012 por 25 Estados miembros, contiene un conjunto de "reglas de oro", que por su carácter vinculante garantizarían el principio de equilibrio presupuestario.

En un mercado común, donde operan las libertades de bienes, servicio, capital y trabajo se le llega a sumar la entrega -parcial o plena- de competencias macroeconómicas y sectoriales (política monetaria y fiscal) a los entes decisorios de carácter supranacional, se constituye una unión económica. Este es el nivel hasta hoy alcanzado por la Unión Europea, donde se cedieron parcialmente políticas monetarias y fiscales.

Estos estamentos obedecen a una lógica progresiva, que como describimos, permitirá entenderlos como secuenciales, es decir, que se transitarían una a una las etapas, otorgando en cada una de ellas mayor trato nacional. Sin embargo, como lo señalan González, Gutiérrez y Martín, en la práctica

6. Tribunal de Justicia de la Unión Europea, "Sentencia de la Corte de 5 de mayo de 1982", Caso Gaston Schul Douane Expediteur BV vs. Inspecteur der Invoerrechten en Accijnzen, Roosendaal, 5 de mayo de 1982. 
esto no es necesariamente así, de hecho, las paradigmáticas comunidades europeas empezaron por la unión tarifaria (de consumidores) antes de liberar bienes y servicios. ${ }^{7}$ Por su parte, cabe señalar, que estos estamentos necesariamente son discriminatorios frente a los terceros ajenos a la zona, toda vez que las libertades otorgadas se fundamentan en el origen, sea de los bienes, servicios, capital y trabajo.

Las comunidades europeas, hoy Unión Europea fueron consolidando uno a uno los estamentos referidos -aunque invirtieron los dos primeros niveles- con base en el funcionalismo o institucionalismo de los años 50 y 70, donde como explicaba Mitrany se produce una especie de transferencia de lealtades entre el Estado nación y los cuerpos supranacionales, dándose a la vez una ramificación de las tareas, es decir, se crearía la necesidad de integrar cada vez más distintas áreas. "Las dimensiones funcionales se determinan a sí mismas. De modo similar la función determina sus órganos apropiados". 8

Más tarde el neofuncionalismo intenta superar las controversias al interior del funcionalismo, que se centraban en la transferencia de políticas, ya que muchos de sus exponentes consideraban que solo la baja política podía ser transferida por el Estado, conservando las áreas de alta política. Al estudiar las comunidades europeas, entendían a la integración como un proceso gradual, donde el éxito dependía, tanto de la transferencia de soberanía a los entes supranacionales, como de la actitud de las masas frente al proceso. ${ }^{9}$ La propuesta neofuncionalista de Jean Monnet, como nos lo recuerda Molina del Pozo, comprendía la idea de que "Europa no se hará de golpe ni en una construcción de conjunto, sino mediante realizaciones concretas, creando primero una solidaridad de hecho". ${ }^{10}$

En contraposición, respondiendo a una lógica conservadora de la soberanía, están los intergubernamentalistas liberales como Moravcsik, que

7. Ver Tremolada, "¿La Alianza del Pacífico facilita la inserción de Colombia en la región Asia Pacífico?", 734.

8. David Mitrany, A working Peace System. An argument for the functional development of international organization (Chicago: Quadrangle Books, 1966); “The Functional Approach to World Organization”, en Theories of Iinternational Relations. Approches to International Relations: Pluralism, ed. Stephen Chan y Cerwyn Moore (Londres: Sage Publications), 1-16.

9. Pedro Canovas, "Planteamientos de la integración. Evolución de la integración en Latinoamérica", III Simposio Grupo de Estudios Jean Monnet, 2002.

10. Carlos Molina del Pozo, Derecho de la Unión Europea (Madrid: Editorial Reus, 2015), 13. 
como explica Oyarzún Serrano, ${ }^{11}$ consideran que un régimen intergubernamental de cooperación política negociada sería exitoso. De ahí que el citado Dromi simplifique los extremos teóricos, recordando que los límites mínimos o máximos de la integración no están definidos, de ahí que se evidencie que los procesos pasan por etapas, desde lo simple o básico, creando vínculos tenues o hasta lo más complejo, que sería la integración política. ${ }^{12}$ En todo caso, como bien lo anota Molina del Pozo, la Unión Europea es "ya federal en muchos de sus elementos, aunque en bastantes ocasiones no se use tal concepto por prejuicio, ignorancia o corrección política". ${ }^{13}$

Adicionalmente, se debe tener en cuenta la orientación de los acuerdos comerciales, si están proyectados hacia el interior estaríamos ante lo que se denominó regionalismo cerrado, donde con el objeto de sustituir las importaciones de países ajenos a la zona, se promueve la industrialización, el proteccionismo y el incremento de barreras arancelarias y no arancelarias a terceros con el fin de proteger y promover la industria intra-zonal, tal como fue el caso de la recomendación cepalina que les sugirió a los países en vías de desarrollo -principalmente exportadores de materias primas y con incipiente industria- producir bienes elaborados y establecer mercados comunes entre naciones con condiciones relativamente homogéneas, dando así, origen -entre otros procesos- a la integración Andina.

El origen de los esquemas de integración en Latinoamérica y el Caribe, se puede explicar tanto por el pensamiento liberal del mundo occidental reinante desde la posguerra, que consideraba al comercio internacional como generador de desarrollo, riqueza y paz, como por la estrategia de la Comisión Económica para América Latina y el Caribe de las Naciones Unidas (CEPAL), que como señalamos, recordaba a los países en vías de desarrollo, principalmente exportadores de materias primas y con una incipiente industria que no podían competir en condiciones de equidad en el nuevo panorama económico mundial, recomendándoles producir bienes elaborados y establecer mercados comunes entre naciones con condiciones relativamente homogéneas. ${ }^{14}$

11. Lorena Oyarzún, "Sobre la naturaleza de la integración regional: teorías y debates", Revista de Ciencia Política 28, $n^{\circ} .2$ (2008): 95-113.

12. Dromi, Ekmekdijan, y Rivera, ed., Derecho comunitario, sistemas de integración régimen del Mercosur, 113.

13. Carlos Molina del Pozo, "Largo camino recorrido desde la descentralización hasta el federalismo: el caso de la Unión Europea", Revista da Secretaria do Tribunal Permanente de Revisão 4, n. 8 (2016): 37.

14. Instituto de Relaciones Europeo-Latinoamericanas, Tres décadas de integración andina: logros y nuevos retos (Madrid: IRELA, 1999), 3. 
En sentido contrario, si la proyección es hacia el exterior, estamos frente al denominado regionalismo abierto ${ }^{15}$ que promueve el establecimiento de acuerdos de comercio abiertos, sometidos a las competencias internacionales e inmerso en el sistema multilateral de comercio. ${ }^{16}$

Por su parte, debemos hacer referencia a las expresiones de integración negativa y positiva, ${ }^{17}$ que acuñó Tinbergen en 1954 y que como nos lo recuerdan los citados Schiff y Winters corresponden a la integración de carácter superficial y profundo, respectivamente. ${ }^{18}$ La primera de ellas comprende la supresión y limitación de las políticas en la zona, a diferencia de los esfuerzos positivos por coordinarlas (trato nacional). A su vez nos precisan que la integración profunda fue una denominación que le dieron Lawrence y Litan, en 1990, a los esfuerzos destinados a una integración más trascendental, de ahí que ellos coincidan en que la expresión se puso en circulación refiriéndose a acuerdos tales como el de la Unión Europea, con el propósito de lograr una unión económica que creara instituciones supranacionales para conseguir dicho objetivo.

Por su parte, Rodrik precisa que Lawrence enfatizaba que en las integraciones superficiales se exige relativamente poco a las políticas nacionales, por el contrario, en una de carácter profundo toda distinción entre política nacional y comercial desaparece, al punto que cualquier uso discrecional de una regulación nacional puede interpretarse como un impedimento al comercio internacional. De esta manera, las reglas internacionales acaban siendo, en efecto, reglas nacionales. ${ }^{19}$

15. Schiff y Winters nos recuerdan que el regionalismo abierto fue una idea de la década de 1990 que se concibió para describir las aspiraciones originales de la APEC y transmitir su plena coherencia con los objetivos multilaterales. Véase Maurice Schiff y Alan Winters, Integración regional y desarrollo (Bogotá: Banco Mundial y Alfaomega Colombiana, 2003).

16. Darío Pereyra, "Comercio e integración en África: el rol de la unión africana” (tesis maestría, Universidad Nacional de La Matanza, Buenos Aires, 2007).

17. Jan Tinbergen, International Economic Integration (Amsterdam: Elsevier, 1954).

18. Schiff y Winters, Integración regional y desarrollo, 163.

19. Dani Rodrik, La paradoja de la globalización (Barcelona: Antoni Bosch, 2012). 


\section{Aciertos y desaciertos del ordenamiento andino y sus reglas de aplicación}

Las estructuras que soportan los ordenamientos de la integración económica, son complejos, vinculantes y con mayor o menor grado de autonomía. Autonomía que debería corresponder al nivel o estamento de integración pactado y no a la necesidad política de los Estados miembros de regirse por organismos intergubernamentales (con escaso o nulo autogobierno) o supranacionales (con altos grados de libertad e independencia).

Este es el debate del que se nutren las denominadas teorías jurídicas de la integración, y que -particularmente en Latinoamérica y el Caribe- explica, por un lado, procesos hiperinstitucionalizados con órganos con escasa autonomía como vemos en el Mercado Común del Sur (Mercosur) ${ }^{20}$ y la Comunidad del Caribe (Caricom), ${ }^{21}$ donde el primero somete las decisiones de sus múltiples órganos al control político de los respectivos congresos, y el segundo, requiere constantemente de consenso de los Estados en la toma de decisiones.

Por otro lado, tendremos procesos hiperinstitucionalizados con órganos supranacionales como es el caso del Sistema Integración Centroamericano (SICA) ${ }^{22}$ y la Comunidad Andina (CAN), ${ }^{23}$ aunque ambos esquemas ejercen la toma de decisiones con timidez, pese a que sus decisiones gozan de aplicación inmediata y preminencia en los ordenamientos internos de los Estados que conforman el bloque. En contraposición, como un proceso infrainstitucionalizado y con nulo autogobierno tenemos a la Alianza del Pacífico, ${ }^{24}$ que -curiosamente- como los cuatro arriba mencionados na-

20. Ver Mercosur, "Textos fundacionales", Mercosur, accedido el 14 de marzo de 2020. «https://bit.ly/36U. $4 \mathrm{fqS}$.

21. Ver Comunidad del Caribe, treaty establishing the caribbean community, 4 de julio de 1973, https://bit. ly/2SJhQJw»; y Caricom, "Nuestro mandato", Caricom, accedido el 14 de marzo de 2020, https://bit. ly/3lDajiè.

22. Ver Sistema de la Integración Centroamericana, "Pilares de la integración", SICA, accedido el 14 de marzo de 2020, ‘https://bit.ly/30XTbpc`; y, Organización de Estados Americanos, "Tratado general de integración económica centroamericana entre los gobiernos de las repúblicas de Guatemala, el Salvador, Honduras y Nicaragua", 4 de junio de 1961, https://bit.ly/34PnaAz».

23. Ver Comunidad Andina, "Ámbitos de acción", CAN, accedido el 14 de marzo de 2020, https://bit. ly/2SQBflg; ; y, Comunidad Andina, "Normativa andina", CAN, accedido el 14 de marzo de 2020, https://bit.ly/30TSLzW.

24. Ver Alianza del Pacífico, "Acuerdo Marco de la Alianza del Pacífico", 6 de junio de 2012, https://bit. ly/3dmjrhD, 
cen con el objetivo de consolidar mercados comunes liberando dentro de la zona pactada, bienes, servicios, capital y trabajo. Procesos -todos- que denotan un divorcio entre la autonomía institucionalizada y el nivel o estamento de integración pactado.

Los ordenamientos de la integración se conciben mediante tratados constitutivos y van sufriendo un largo y trabajoso proceso de desarrollo y consolidación, mediante la práctica institucional, la jurisprudencia y la doctrina. De ahí, que con base en el rol protagónico del Tribunal Andino en esta tarea, los doctrinantes y estudios anteriores procedamos presentar un análisis de la estructura del ordenamiento Andino. ${ }^{25}$ El Tribunal Andino, en la segunda mitad de los años ochenta, siguiendo el ejemplo del Tribunal de Justicia de las Comunidades Europeas, como nos lo recuerda Quindimil López, destacó los elementos estructurales que configuran el derecho de la integración andina como un auténtico derecho comunitario y a la CAN como una comunidad de Derecho. ${ }^{26}$

Con ocasión de que la República de Colombia interpusiera dos acciones de nulidad contra las Resoluciones 252 y 253 de la Junta, el Tribunal Andino, el 10 de junio de 1987, empezó a precisar que el ordenamiento jurídico del Acuerdo de Cartagena "Regula las relaciones de sus integrantes y todo el proceso de la integración en el Pacto Andino, y que es una manifestación de la soberanía conjunta y compartida de los Países Miembros, por lo que no puede ser desconocido y tampoco alterado por ninguno de ellos, mucho menos por sus órganos de gobierno". ${ }^{27}$

No obstante, como bien señala Quindimil López, ${ }^{28}$ es en su segundo pronunciamiento cuando el Tribunal de Justicia hace una mayor contribución al desarrollo y consolidación del derecho Comunitario Andino, al establecer el carácter imperativo y obligatorio del ordenamiento jurídico andino, extensivo a todos los sujetos (personas físicas o jurídicas, públicas o privadas, nacionales o comunitarias, sin excepción), y cuando utiliza la

25. Erick Tremolada, "El Derecho Andino: Una Sistematización Jurídica para la Supervivencia de la Comunidad Andina de Naciones", Cuadernos Constitucionales de la Cátedra Fadrique Furió Ceriol, n. ${ }^{\circ} 57$ (2006): 35-75.

26. Jorge Quindimil, Instituciones y Derecho de la Comunidad Andina (Valencia: Tirant lo Blanch, 2006), $169-70$.

27. Tribunal de Justicia de la Comunidad Andina, "Sentencia de nulidad del 10 de junio de 1987", Proceso 02-N-86, 10 de junio de 1987.

28. Jorge Quindimil, Instituciones y Derecho de la Comunidad Andina, 171. 
expresión Comunidad de Derecho para referirse al entramado jurídico institucional del Acuerdo de Cartagena

El ordenamiento jurídico del Acuerdo de Cartagena es imperativo, de aplicación obligatoria en todos los países miembros, y que debe ser respetado y cumplido por todos ellos y por supuesto por los órganos del Acuerdo, lo mismo que por todos los organismos y funcionarios que ejercen atribuciones conforme a dicho ordenamiento, el cual regula el proceso de la integración que se cumple en una comunidad de derecho cual es la constituida en el Pacto Andino. ${ }^{29}$

En estas dos resoluciones el Tribunal Andino, sigue la corriente interpretativa del Tribunal de Justicia de las Comunidades Europeas, se fundamenta en las paradigmáticas sentencias Van Gend en Loos de 5 de febrero de 1963 y Costa c. ENEL de 15 de julio de 1964, donde también se califica al Derecho Comunitario, no como un mero agregado de normas, sino como un ordenamiento jurídico propio. Así, el Tribunal de Justicia de la Comunidad Andina ha venido particularizando en forma paulatina su análisis de los elementos y aspectos que integran y caracterizan el Derecho Comunitario Andino, partiendo de su sistema de fuentes originarias y derivadas. Entendidas estas como aquellos métodos o formas particularizadas por las que un orden jurídico crea sus propias normas, permitiéndonos identificar las normas que lo componen, así como los mecanismos de interpretación y aplicación. ${ }^{30}$

El orden jurídico andino, está conformado, en primer lugar, por sus fuentes normativas directas, esto es, el Derecho primario u originario que constituye un primer nivel normativo compuesto por el Acuerdo de Cartagena, sus protocolos modificatorios e instrumentos adicionales y el Tratado de Creación del Tribunal de Justicia y su protocolo modificatorio de Cochabamba, y además, por un Derecho secundario o derivado jerarquizado en dos niveles, un segundo nivel que se integra con las decisiones del Consejo Andino de Ministros de Relaciones Exteriores y la Comisión y con las resoluciones de la Secretaría que desarrollan directamente previsiones del Acuerdo de Cartagena (competencia legislativa) y un tercer nivel constituido por las otras resoluciones de la Secretaría (competencia administrativa). Estamos pues frente a una estructura vertical con tres niveles

29. Tribunal de Justicia de la Comunidad Andina, "Sentencia de 16 de abril de 1986", Proceso 02-AN-86, 16 de abril de 1986.

30. Ver Mangas y Liñan, Instituciones y Derecho de la Unión Europea (Madrid: Tecnos, 2005), 333-4. 
normativos y con diferenciación jerárquica entre sus modalidades, excepto en el segundo nivel, donde tal como sucede en el ordenamiento europeo, da igual en términos jerárquicos utilizar Reglamentos o Directivas: ${ }^{31}$

[...] El desarrollo de los diferentes programas que como principios u objetivos generales se fijan en el Acuerdo, requiere en muchos casos de implementación posterior o de normas de ejecución del Acuerdo para que puedan hacerse efectivas dentro de los Países Miembros. Esas normas que deben sujetarse a los tratados que representan la cima de la pirámide legal, forman el derecho derivado o secundario, cuya elaboración legislativa ha sido atribuida a la Comisión de la Comunidad Andina, la que antes de la Ratificación del Protocolo de Trujillo suscrito el 10 de marzo de 1996 mantenía la <capacidad legislativa exclusiva sobre materias de su competencia> (artículo 6 de la Decisión 236) y ahora la comparte con el Consejo Andino de Ministros de Relaciones Exteriores con facultad de expedir Decisiones que forman < parte del ordenamiento jurídico de la Comunidad Andina> (artículo 17 del Acuerdo reformado, Decisión 406, Codificación del Acuerdo de Integración Subregional Andino, publicada en la Gaceta Oficial n² 273 de 4 de julio de $1997 .^{32}$

La supranacionalidad del ordenamiento andino no sería suficiente, a menos que su derecho cuente con mecanismos propios de aplicación que garanticen la incursión del mismo en los ordenamientos jurídicos estatales, toda vez que estos, muchas veces no solo son contrarios, sino incluso hostiles a los principios de la integración. Por esta razón, todo ordenamiento supranacional de integración posee características y atributos propios que lo blindan y le permiten superar las posibles incompatibilidades; nos referimos a la intangibilidad, a su carácter vinculante, a la aplicabilidad directa, a los efectos directos e inmediatos y a la preeminencia, todos frutos de su autonomía, permitiéndole penetrar el orden jurídico interno de los Estados miembros, de ahí la necesidad del Tribunal Andino de dimensionar la noción de supranacionalidad:

[...] La comprensión de este término dentro de la teoría jurídica contemporánea, nos aleja tanto de la definición estrictamente etimológica del mismo, como de la

31. Ver Carlos Molina del Pozo, "Los actos normativos derivados de las competencias establecidas en el Tratado Constitucional de la Unión Europea", Anuario de la Facultad de Derecho de Alcalá de Henares (2005): 125-73.

32. Tribunal de Justicia de la Comunidad Andina, "Sentencia de nulidad del 26 de febrero de 1998", Proceso 01-AN-97, 26 de febrero de 1998. 
dada por los constitucionalistas y la propia Ciencia Política. El escozor que esta noción produce en muchos espíritus, se debe precisamente a un enfoque etnocentrista de la misma, juzgándose con criterios valorativos propios del derecho político tradicional, esta concepción novísima y al mismo tiempo respetuosa de la soberanía interna de los Estados miembros, gracias a cuyo apoyo político surge el nuevo ente o comunidad vertebrada en torno a fines comunes a lograr (...) el término ya no podría sostenerse en puridad de verdad, hoy en día, como expresión de la idea de un Súper Estado con soberanía territorial propia. Todo lo contrario, la noción de supranacionalidad dentro del derecho de la integración, es la negación del Imperium a la manera romana, y la afirmación de la autonomía de gestión que crean los Estados que se integran $[\ldots]^{33}$

Así, los Estados miembros siguen siendo los titulares del poder político, que solo han cedido parcialmente para determinado propósito. El goce de personalidad jurídica internacional de una organización internacional no es plena como la de los Estados, por el contrario, está limitada a los objetivos y funciones que le fueron confiadas, brindándole autonomía al nuevo ente, pero afectada por el principio de especialidad. ${ }^{34}$

Se trata, en últimas, e interpretando las palabras del profesor Pierre Pescatore, de la aceptación de los Estados de un conjunto de valores comunes que dotan de objetivo y directrices y donde los participantes están dispuestos a subordinar sus intereses nacionales y su jerarquía nacional de valores. ${ }^{35}$

Ello hace que el derecho de la integración, en general, y el derecho andino en particular, se distingan del derecho internacional público clásico, así como de los derechos nacionales, con los que, paradójicamente forma parte y los integra. De ahí, que los Estados miembros no pueden modificar

33. Solicitud de interpretación prejudicial de los arts. 63 y 70 de la Decisión 85 de la Comisión del Acuerdo de Cartagena, y art. 119 de la Decisión 313 de la misma Comisión, remitida por el Consejo de Estado de la República de Colombia, Sala de lo Contencioso Administrativo, Sección Primera, en el asunto de la Societè Nationale D'exploitation Industrielle des Tabacs et des Allumettes (SEITA), que interpuso una Acción de Nulidad y Restablecimiento de Derecho, contra los actos de la División de Propiedad Industrial de la Superintendencia de Industria y Comercio y del superintendente delegado para la propiedad industrial. Tribunal de Justicia de la Comunidad Andina, "Sentencia de nulidad de 27 de marzo de 1995", Proceso 05-IP-95, 27 de marzo de 1995.

34. José Sobrino, "El derecho de integración. Marco conceptual y experiencia en la Unión Europea", en Integración y supranacionalidad: soberanía y derecho comunitario en los países andinos, ed. Secretaría General de la Comunidad Andina y Programas de Cooperación Andina a Bolivia PCAB (Lima: Comunidad Andina, 2001), 29-69.

35. Pierre Pescatore, Derecho de la integración: nuevo fenómeno en las relaciones internacionales (Buenos Aires: BID Intal, 1973), 42-3. 
unilateralmente las normas adoptadas en el seno de la Comunidad, y de hacerlo generarían responsabilidad internacional para su Estado:

[...] establece el Principio de la Intangibilidad en el Derecho comunitario, al disponer que: <La Comisión es el órgano máximo del Acuerdo y como tal tiene la capacidad de legislación exclusiva sobre las materias de su competencia>. Así se establece con claridad que ninguna autoridad nacional puede al margen de la Comisión modificar o establecer reglas no previstas por los Ministros de Industria de los Países Miembros o los Plenipotenciarios debidamente acreditados que integran la Comisión y que tienen la capacidad exclusiva para legislar por medio de las Decisiones $[\ldots]^{36}$

Intangibilidad que implica para los socios comunitarios que adquieren derechos y obligaciones, estas últimas se materializan en obligaciones de hacer y de no hacer tal como se prevé en el artículo 40 del Tratado de Creación del Tribunal de Justicia:

Los Países Miembros están obligados a adoptar las medidas que sean necesarias para asegurar el cumplimiento de las normas que conforman el ordenamiento jurídico de la Comunidad Andina. Se comprometen, asimismo, a no adoptar ni emplear medida alguna que sea contraria a dichas normas o que de algún modo obstaculice su aplicación.

Por su parte, los primeros artículos del Tratado de Creación del Tribunal de Justicia de la Comunidad Andina, recogen dos atributos que mejoran cualitativamente el ordenamiento jurídico comunitario. Nos referimos a la aplicabilidad directa y la preeminencia. El primero de estos consiste en que, tan pronto la norma jurídica comunitaria nace, automáticamente se integra en el ordenamiento jurídico interno de los países, y por ello -como lo anota Kaune- rige en todo el territorio que integra la Comunidad Andina y lleva consigo la connotación de efecto directo. ${ }^{37} \mathrm{El}$ segundo atributo hace refe-

36. Esta característica de intangibilidad del ordenamiento jurídico andino fue reiterada por el Tribunal de Justicia de la Comunidad en la citada solicitud de interpretación prejudicial de los arts. 63 y 70 de la Decisión 85 de la Comisión del Acuerdo de Cartagena, y art. 119 de la Decisión 313 de la misma Comisión. Tribunal de Justicia de la Comunidad Andina, "Sentencia de nulidad de 27 de marzo de 1995", Proceso 05-IP-95, 27 de marzo de 1995.

37. Kaune Arteaga, "La necesidad de la integración, orden y ordenamiento jurídico comunitario", en Testimonio Comunitario- Doctrina, Legislación, Jurisprudencia, ed. Tribunal de Justicia de la Comunidad Andina (Quito: TJCA, 2004). 
rencia a la supremacía de las normas comunitarias de derecho originario y de derecho derivado, sobre las normas jurídicas de derecho interno.

El Tribunal, ha destacado la importancia de estas características hasta el punto de considerar que la existencia misma del derecho comunitario andino depende de la presencia de tales atributos "La sola suposición de que las Decisiones de la Comisión o las Resoluciones de la Junta, tuvieran que pasar por el tamiz legislativo de cada uno de los Países Miembros, antes de su aplicación interna, habría conducido a negar la existencia de un derecho comunitario andino". 38

Soporta el Tribunal su aseveración citando al profesor Gil Carlos Rodríguez Iglesias, que define la aplicabilidad directa de la norma comunitaria "como la capacidad de la misma para producir efectos jurídicos en un País Miembro sin que se requiera ningún complemento normativo de derecho interno". De igual manera hace con Muñoz Machado, al referir que una regla o norma "goza de aplicabilidad directa cuando no precise que los Estados Miembros dicten normas de incorporación, transposición o desarrollo para darle efectividad dentro de su territorio", y con el profesor Dámaso Ruiz- Jarabo Colomer, quién define el principio manifestando que:

La aplicabilidad inmediata significa que la norma comunitaria adquiere, automáticamente, de por sí, estatuto de derecho positivo en el orden interno de los Estados a que va dirigida. Ello supone que la norma comunitaria se integra de pleno derecho en ese orden interno, sin necesidad de ninguna fórmula de introducción o de recepción, que se impone en cuanto tal derecho comunitario y que genera en todo juez nacional la obligación de aplicarla (...) El derecho comunitario, por consiguiente, además de ser un ordenamiento jurídico autónomo, con su propio sistema de producción normativa, posee una fuerza específica de penetración en el orden jurídico interno de los Estados Miembros nacida de su propia naturaleza, que se manifiesta en su aplicabilidad inmediata y, fundamentalmente, en su efecto directo y su primacía”. ${ }^{39}$

39. Pronunciamiento dado en la Acción de incumplimiento interpuesta por la Junta del Acuerdo de Cartagena contra la República de Venezuela, por supuesta contravención a las resoluciones 397 y 398 expedidas por la Junta el 14 de marzo de 1996 de los arts. 41, 42, 43 y 46 del Acuerdo de Cartagena, del art. $5^{\circ}$ del Tratado de Creación del Tribunal de Justicia del Acuerdo de Cartagena y 13 de la Decisión 328 de la Comisión sobre Sanidad Agropecuaria Andina. Tribunal de Justicia de la Comunidad Andina, "Sentencia de 24 de marzo de 1997", Proceso 03-AI-96, 24 de marzo de 1997.

39. Ibíd. 
La aplicabilidad directa del derecho comunitario deriva de las propias normas positivas de carácter constitutivo u originario. El Tratado de Creación del Tribunal de Justicia establece en el art. 2o que "las Decisiones obligan a los Países Miembros desde la fecha en que sean aprobadas por la Comisión", mientras que en el art. 30 se señala que "Las Decisiones de la Comisión serán directamente aplicables en los Países Miembros a partir de la fecha de su publicación en la Gaceta Oficial del Acuerdo, a menos que las mismas señalen una fecha posterior" y que solo "cuando su texto así lo disponga, las Decisiones requerirán de incorporación al derecho interno, mediante acto expreso en el cual se indicará la fecha de su entrada en vigor en cada País Miembro".

El segundo atributo que caracteriza al derecho comunitario andino, es el que tiene que ver con aquella virtualidad que tienen sus normas de prevalecer sobre las de derecho interno, cualquiera que sea el rango de estas. Esto quiere decir, que cuando existe contradicción entre una norma comunitaria y una norma interna, prevalecerá la primera en virtud del principio de aplicación directa y de los efectos inmediatos que esta conlleva. Así, adoptada una decisión o emitida una resolución, automáticamente entra a formar parte del ordenamiento jurídico interno de los estados miembros una vez haya sido publicada en la Gaceta Oficial del Acuerdo de Cartagena sin que se requiera instrumento adicional para su incorporación, a menos, que expresamente se haya convenido lo contrario.

En consecuencia, en aplicación de los principios y características anteriormente descritos, en el art. 40 del Tratado de Creación del Tribunal, en el que se tutelan tanto la aplicabilidad directa e inmediata y el consecuente efecto directo, ambos derivados de la indispensable preeminencia de su ordenamiento jurídico, se le imponen a los países miembros dos obligaciones básicas con respecto al mismo:

[...] una, de hacer, dirigida a la adopción de medidas que aseguren el cumplimiento de dicho Ordenamiento dentro de su ámbito territorial y otra, de no hacer, conducente a que no se adopten medidas o se asuman conductas o se expidan actos, sean de naturaleza legislativa, judicial, o administrativa, que contraríen u obstaculicen la aplicación del derecho comunitario $[. . .]^{40}$

40. Tribunal de Justicia de la Comunidad Andina, "Sentencia de 25 de enero de 1999", Proceso 07-AI-99, 25 de enero de 1999. 
Ahora bien, el principio de preeminencia no solo ha sido positivado en los arts. 20 y 30 del Tratado de Creación del Tribunal de Justicia de la Comunidad, también se prevé en el Reglamento de Procedimientos Administrativos de la Secretaría General de la Comunidad Andina, Decisión 425, que señala "las Resoluciones de la Secretaría General entrarán en vigencia y producirán sus efectos a partir de la fecha de su publicación en la Gaceta Oficial del Acuerdo de Cartagena, salvo que la propia Resolución señale una fecha distinta"

\section{Colofón}

El ordenamiento andino es una compleja organización cohesionada, coherente y que ha alcanzado un desarrollo y una madurez que garantiza la eficacia de sus normas y que faculta a los órganos comunitarios para producir Derecho con capacidad de producir efectos jurídicos en cada país miembro sin que se requiera ningún complemento normativo de Derecho interno, siendo fuente inmediata de derechos y obligaciones para todos aquellos a quienes afecta, permitiendo la posibilidad de que los particulares puedan exigir directamente su observancia ante sus respectivos autoridades administrativas, jueces y/o tribunales.

Estamos así frente a un ordenamiento jurídico autónomo e independiente, fundamentado en la técnica de la supranacionalidad que produce, aplica y ejecuta normas según las reglas de juego adoptadas para este efecto. Parafraseando a Pescatore, la supranacionalidad se traduce en la existencia de un poder real y autónomo puesto al servicio de los objetivos comunes de los Estados, ${ }^{41}$ que aplica de forma inmediata y directa en los ordenamientos nacionales, gozando de primacía frente al Derecho interno de los países miembros. Esto, en virtud del consentimiento estatal expresado en los Tratados Constitutivos y porque proviene de los organismos creados para el efecto.

Pese al creer de muchos, esta compleja organización de Derecho de la integración cumple con las características básicas para que se predique su eficacia, toda vez que como diría Viana, se trata de un orden pleno, porque supone un sistema integral y originario de elaboración de normas, y a su

41. Pescatore, Derecho de la integración: nuevo fenómeno en las relaciones internacionales, 43. 
vez, es autónomo, porque está soportado en una organización independiente y eficaz. ${ }^{42}$ Espíndola y Herrera, refiriéndose a la eficacia, hacen énfasis en la virtud, fuerza e idoneidad para lograr un determinado objetivo dentro de los fines previstos, produciendo efectos jurídicos que se respetan y aplican, y en caso de incumplimiento, los órganos comunitarios imponen las sanciones correspondientes. ${ }^{43}$

No obstante, pese a la claridad que nos brinda su ordenamiento, la eficacia del derecho andino se confunde con la tendencia utilitarista y la ambivalente decisión política de los gobiernos que a lo largo de estos cincuenta años han regido los destinos de los Estados que componen la Comunidad. Estos insisten en un proceso multidimensional, que incluye aspectos sociales, culturales y políticos, que bien pueden desarrollarse en el ámbito intergubernamental, pero que les es instrumental para aplazar los desarrollos económicos conjuntos, toda vez que -y esta es una de sus sombras más oscuras- no confían en sus socios y los ven como competidores en una economía global. Esto, sumado al alto grado de presidencialismo ${ }^{44}$ que se resiste al ejercicio de las competencias cedidas y a unas agendas nacionales fuertemente ideologizadas, conspira contra la eficacia de un orden cincuentenario. $\mathrm{Pa}$ rece que en Latinoamérica y el Caribe, la suerte del proceso, no será como en Europa, esto es de arriba hacia abajo, y tendremos que ser los particulares (personas naturales y jurídicas) los que exijamos a los órganos comunitarios y a los Estados que ejerzan una planeación operativa, una fiscalización de obligaciones y un fomento que proteja y promueva la integración andina de conformidad con las previsiones del Acuerdo de Cartagena y demás tratados constitutivos. El derecho a una buena administración Andina no solo debería ser un principio rector para sus órganos y Estados miembros, debería entenderse como un derecho fundamental de los ciudadanos. ${ }^{45}$

42. Andrée Viana, "Sistema de solución de controversias en la Comunidad Andina", Foro constitucional iberoamericano, n. ${ }^{\circ} 10$ (2005): 123-35.

43. Carlos Espíndola y Diana Herrera, "El sistema jurídico andino: ¿utopía o realidad jurídica?", Criterio Jurídico 8, n. ${ }^{\circ} 1$ (2008): 35-64.

44. Ver Erick Tremolada, "El Sistema Institucional andino frente a su referente europeo", Cuadernos Constitucionales de la Cátedra Fadrique Furió Ceriol, n. 56 (2008): 115-46; y El Derecho Andino en Colombia (Bogotá: Universidad Externado de Colombia, 2006), 25-8.

45. Ver Carlos Molina del Pozo, "El código europeo de buena conducta administrativa como instrumento esencial para la aplicación práctica del derecho a una buena administración”, Derecho y Economía de la Integración, n. ${ }^{\circ} 6$ (2018): 111-21. 


\section{Bibliografía}

Alianza del pacífico. "Acuerdo Marco de la Alianza del Pacífico". 6 de junio de 2012, 〈https://bit.ly/3dmjrhD.

Balassa, Bela. "Tariff Reductions and Trade in Manufactures among the Industrial Countries". En Comparative Advantage, Trade Policy and Economic Development, 131-9. London: Harvester Wheatsheaf, 1989.

Balassa, Bela. "Trade Creation and Trade Diversion in the European Common Market: An Appraisal of the Evidence". Manchester School of Economic and Social Studies 42, n. 2 (1974): 93-135.

Canovas, Pedro. "Planteamientos de la integración. Evolución de la integración en Latinoamérica". III Simposio Grupo de Estudios Jean Monnet. 2002. 〈https:// bit.ly/2Ifja4F.

Caricom. "Nuestro mandato". Caricom. Accedido el 14 de marzo de 2020, hhttps://bit. ly/31Dajies.

Comunidad Andina. "Ámbitos de acción". CAN. Accedido el 14 de marzo de 2020. https://bit.ly/2SQBflg .

"Normativa andina". CAN. Accedido el 14 de marzo de 2020, https://bit. ly/30TSLzW

Comunidad del Caribe. treaty establishing the caribbean community. 4 de julio de 1973, 〈https://bit.ly/2SJhQJw〉.

Dromi, Roberto, Miguel Angel Ekmekdijan, y César Rivera, ed. Derecho comunitario, sistemas de integración régimen del Mercosur. Buenos Aires: Ciudad Argentina, 1995.

Espíndola, Carlos, y Diana Herrera. "El sistema jurídico andino: ¿utopía o realidad jurídica?. Criterio Jurídico 8, n. 1 (2008): 35-64. https://bit.ly/3iPrMMe».

Instituto de Relaciones Europeo-Latinoamericanas. Tres décadas de integración andina: logros y nuevos retos. Madrid: IRELA, 1999.

Kaune Arteaga. "La necesidad de la integración, orden y ordenamiento jurídico comunitario". En Testimonio Comunitario- Doctrina, Legislación, Jurisprudencia, editado por Tribunal de Justicia de la Comunidad Andina. Quito: TJCA, 2004. 〈https://bit.ly/2IkJvOZ〉.

Mangas, Martín, y Diego Liñan. Instituciones y Derecho de la Unión Europea. 5a ed. Madrid: Tecnos, 2005.

Mercosur. "Textos fundacionales". Mercosur. Accedido el 14 de marzo de 2020. ‘https://bit.ly/36U4fqS.

Mitrany, David. A working Peace System. An argument for the functional development of international organization. Chicago: Quadrangle Books, 1966.

"The Functional Approach to World Organization". En Theories of International Relations. Approches to International Relations: Pluralism, editado por Stephen Chan y Cerwyn Moore, 1-16. Londres: Sage Publications. 
Molina del Pozo, Carlos. "El código europeo de buena conducta administrativa como instrumento esencial para la aplicación práctica del derecho a una buena administración”. Derecho y Economía de la Integración, n. 6 (2018): 111-21.

. "Largo camino recorrido desde la descentralización hasta el federalismo: el caso de la Unión Europea". Revista da Secretaria do Tribunal Permanente de Revisão 4, n. ${ }^{\circ} 8$ (2016): 19-40.

. Derecho de la Unión Europea. 2ª ed. Madrid: Editorial Reus, 2015.

. "Los actos normativos derivados de las competencias establecidas en el Tratado Constitucional de la Unión Europea". Anuario de la Facultad de Derecho de Alcalá de Henares, (2005): 125-73. https://bit.ly/3dgOWKf〉.

Oyarzún, Lorena. "Sobre la naturaleza de la integración regional: teorías y debates". Revista de Ciencia Política 28, nº 2 (2008): 95-113. doi:10.4067/S0718090X2008000200004

Organización de Estados Americanos. "Tratado general de integración económica centroamericana entre los gobiernos de las repúblicas de Guatemala, el Salvador, Honduras y Nicaragua". 4 de junio de 1961. https://bit.ly/34PnaAz .

Pereyra, Darío. "Comercio e integración en África: el rol de la unión africana". Tesis maestría, Universidad Nacional de La Matanza, Buenos Aires, 2007. https:// bit.ly/2SKWSK7?.

Pescatore, Pierre. Derecho de la integración: nuevo fenómeno en las relaciones internacionales. Buenos Aires: BID Intal, 1973.

Quindimil, Jorge. Instituciones y Derecho de la Comunidad Andina. Valencia: Tirant lo Blanch, 2006.

Rodrik, Dani. La paradoja de la globalización. Barcelona: Antoni Bosch, 2012.

Schiff, Maurice, y Alan Winters. Integración regional y desarrollo. Bogotá: Banco Mundial y Alfaomega Colombiana, 2003.

Sobrino, José. "El derecho de integración. Marco conceptual y experiencia en la Unión Europea”. En Integración y supranacionalidad: soberanía y derecho comunitario en los países andinos, editado por Secretaría General de la Comunidad Andina y Programas de Cooperación Andina a Bolivia PCAB, 29-69. Lima: Comunidad Andina, 2001.

Sistema de la Integración Centroamericana. "Pilares de la integración". SICA. Accedido el 14 de marzo de 2020. https://bit.ly/30XTbpcs.

Tinbergen, Jan. International Economic Integration. Amsterdam: Elsevier. 1954.

Tremolada, Erick. "La Alianza del Pacífico: ¿marketing sin contenido?". En Nuevas propuestas de integración regional: tendencias y retos de transformación, editado por Catherine Ortiz y Edgar Vieira, 267-305. Bogotá: Fondo Editorial - Ediciones Universidad Cooperativa, 2019.

"La Alianza del Pacífico: ¿una sobrevalorada integración?". Studi sull' integrazione europea 11, n. ${ }^{\circ} 1$ (2016): 21-40.

" ¿La Alianza del Pacífico facilita la inserción de Colombia en la región Asia Pacífico?". Papel Político 19, n. ${ }^{\circ} 2$ (2014): 721-52. 
- "El Derecho Andino: Una Sistematización Jurídica para la Supervivencia de la Comunidad Andina de Naciones". Cuadernos Constitucionales de la Cátedra Fadrique Furió Ceriol, n. ${ }^{\circ} 57$ (2006): 35-75. https://bit.ly/3jP1Q4E).

. "El Sistema Institucional andino frente a su referente europeo". Cuadernos Constitucionales de la Cátedra Fadrique Furió Ceriol, n. 56 (2008): 115-46. https://bit.ly/36SWX6U.

. El Derecho Andino en Colombia, Bogotá: Universidad Externado de Colombia, 2006.

Tribunal de Justicia de la Unión Europea. "Sentencia de la Corte de 5 de mayo de 1982". Judgment of 5 May 1982. Gaston Schul Douane Expediteur BV contra Inspecteur der Invoerrechten en Accijnzen, Roosendaal. 5 de mayo de 1982. https://bit.ly/31CGyaG .

Tribunal de Justicia de la Comunidad Andina. "Sentencia de nulidad del 26 de febrero de 1998". Proceso 01-AN-97. 26 de febrero de 1998.

. "Sentencia de nulidad de 27 de marzo de 1995". Proceso 05-IP-95. 27 de marzo de 1995.

. "Sentencia de nulidad de 27 de marzo de 1995". Proceso 05-IP-95. 27 de marzo de 1995.

. "Sentencia de 24 de marzo de 1997". Proceso 03-AI-96. 24 de marzo de 1997.

. "Sentencia de 25 de enero de 1999". Proceso 07-AI-99. 25 de enero de 1999.

Viana, Andrée. "Sistema de solución de controversias en la Comunidad Andina". Foro constitucional iberoamericano, n. $^{\circ} 10$ (2005): 123-35.

Viner, Jacob. The Customs Union Issue. Nueva York: Fundación Carnegie para la Paz Internacional, 1950. 